Full-length article

\title{
Caspase-1 inhibitor AC-YVAD-CHO attenuates quinolinic acid-induced increases in p53 and apoptosis in rat striatum ${ }^{1}$
}

\author{
Yi CAO, Zhen-lun GU, Fang LIN, Rong HAN, Zheng-hong QIN ${ }^{2}$ \\ Department of Pharmacology, Soochow University School of Medicine, Suzhou 215007, China
}

\section{Key words}

caspase 1; Ac-YVAD-CHO; Huntington disease; protein p53; NF-kappaB inhibitor alpha; apoptosis; NF-kappaB

${ }^{1}$ Project supported by the National Natural Science Foundation of China (№ 30370506).

${ }^{2}$ Correspondence to Zheng-hong QIN, PhD.

Phn 86-512-6512-2087.

Fax 86-512-6519-0599.

Email zhqin5@hotmail.com

Received 2004-07-21

Accepted 2004-10-25

doi: $10.111 / \mathrm{j} .1745-7254.2005 .00025 . \mathrm{x}$

\begin{abstract}
Aim: To study the effects of the caspase-1 inhibitor Ac-YVAD-CHO on quinolinic acid (QA)-induced apoptosis. Methods: Rats were pre-treated with intrastriatal infusion of Ac-YVAD-CHO (2-8 $\mu \mathrm{g})$ before intrastriatal injection of QA (60 nmol). Striatal total proteins, genomic DNA, and nuclear proteins were isolated. The effects of Ac-YVAD-CHO on QA-induced caspase-1 activity, internucleosomal DNA fragmentation, IKB- $\alpha$ degradation, NF- $\mathrm{KB}$, and AP-1 activation, and increases in 553 protein levels were measured with enzyme assays, agarose gel electrophoresis, electrophoresis mobility shift assays, and Western blot analysis. Results: Pre-treatment with Ac-YVAD-CHO inhibited QA-induced internucleosomal DNA fragmentation. Ac-YVAD-CHO inhibited QA-induced increases in caspase-1 activity and p53 protein levels, but had no effect on QA-induced IкB- $\alpha$ degradation, NF- $\mathrm{KB}$ or AP-1 activation. Conclusion: Caspase-1 is involved in QA-induced $\mathrm{p} 53$ upregulation but not IкB- $\alpha$ degradation. Inhibition of caspase-1 attenuates QA-induced apoptosis in rat striatum.
\end{abstract}

\section{Introduction}

Excitotoxin-induced degeneration of striatal neurons in amimals has been used as an animal model of Huntington's disease (HD). Recent studies in transgenic animal models of HD demonstrated increased response of striatal neurons to excitotoxin, supporting a role of glutamate receptors in $\mathrm{HD}^{[1]}$. Excitotoxins acting on $N$-methyl- $D$-aspartate (NMDA) and kainic acid (KA) receptors will induce destruction of striatal GABAergic neurons by apoptotic mechanisms ${ }^{[2-4]}$. Caspases and tumor suppresser p53 play essential roles in apoptosis in a variety of cells including neurons ${ }^{[5-8]}$. Previous studies have reported that excitotoxin induces the activation of caspases and induces p53 expression ${ }^{[9-11]}$. Excitotoxin also reportedly activates nuclear factor-kappaB $(\mathrm{NF}-\kappa \mathrm{B})$, but the mechanism by which this occurs remains unknown ${ }^{[12,13]}$.

Recent studies have demonstrated that quinolinic acid (QA) induced significant increases in NF- $\kappa \mathrm{B}$ binding activity in the nucleus ${ }^{[14]}$. NF- $\kappa B$ nuclear translocation mediates the upregulation of p53 and c-Myc in striatal neurons exposed to excitotoxic injury ${ }^{[15-17]}$. NMDA receptors activate $\mathrm{NF}-\kappa \mathrm{B}$ by selective degradation of an inhibitor protein, I $\mathrm{I} B-\alpha$.
Excitotoxin-induced degradation of I $\mathrm{KB}-\alpha$ involves a caspase-3-dependent mechanism in rat striatum and can be blunted by a caspase- 3 inhibitor and a free radical scavenger $^{[18,19]}$. In the present study we evaluated the role of caspase-1 inhibitor Ac-YVAD-CHO in QA-induced NF- $\kappa \mathrm{B}$ activation, p53 induction, and apoptosis.

\section{Materials and methods}

Stereotaxic drug administration Sprague-Dawley rats (300-350 g) were obtained from the Experimental Animal Center of Soochow University (Certificate № 20020008, Grade II). Rats were anesthetized with pentobarbital sodium (50 $\mathrm{mg} / \mathrm{kg}$ ). Stereotaxic drug administration was performed using a Kopf stereotaxic apparatus as described by Qin et $a l^{[3]}$. To study the effects of a caspase-1 inhibitor on QA-induced internucleosomal DNA fragmentation, rats were either pretreated with an intrastriatal infusion of Ac-YVAD-CHO (2-8 $\mu \mathrm{g})$ or $\mathrm{Me}_{2} \mathrm{SO}(2 \mu \mathrm{L}) 10 \mathrm{~min}$ before instrastriatal injection of QA (60 nmol) and then killed $24 \mathrm{~h}$ after QA administration, or pre-treated with intrastriatal infusion of Ac-YVAD-CHO (4 $\mu \mathrm{g}) 10 \mathrm{~min}$ before instrastriatal injection of QA $(60 \mathrm{nmol})$ and 
killed 12, 24, or $48 \mathrm{~h}$ after QA administration. Striatal genomic DNA was isolated and electrophoresed on a $2 \%$ agarose gel. To study the effect of a caspase-1 inhibitor on QA-induced increases in caspase- 1 activity, rats were pre-treated with an intrastriatal infusion of Ac-YVAD-CHO $(4 \mu \mathrm{g})$ or $\mathrm{Me}_{2} \mathrm{SO}(2$ $\mu \mathrm{L}) 10 \mathrm{~min}$ before intrastriatal injection of QA $(60 \mathrm{nmol})$ and then killed $12 \mathrm{~h}$ after QA treatment. Striatal homogenates were used for assay of caspase-1 activity. To study the effect of a caspase-1 inhibitor on QA-induced increases in p53 proteins and NF- $\kappa \mathrm{B}$ and AP-1 binding activities, rats were pre-treated with intrastriatal infusion of Ac-YVAD-CHO $(4 \mu \mathrm{g})$ or $\mathrm{Me}_{2} \mathrm{SO}(2 \mu \mathrm{L}) 10 \mathrm{~min}$ before intrastriatal injection of QA (60 nmol) and then killed $24 \mathrm{~h}$ after QA treatment. Total striatal proteins were extracted for Western blot analysis. Other animals were killed $12 \mathrm{~h}$ after QA treatment and nuclear proteins were isolated from the striatum for an electrophoresis mobility shift assay.

Isolation of genomic DNA and electrophoresis Striatal genomic DNA was prepared as described by Qin et $a l^{[3]}$. Briefly, striatal tissues were homogenized in a buffer containing $\mathrm{NaCl} 100 \mathrm{mmol} / \mathrm{L}$, edetic acid $25 \mathrm{mmol} / \mathrm{L}$, Tris- $\mathrm{HCl} 10$ $\mathrm{mmol} / \mathrm{L}(\mathrm{pH} 8.0$ ), 0.5\% SDS, and RNase A $0.5 \mathrm{mg} / \mathrm{L}$. Homogenates were incubated at $55^{\circ} \mathrm{C}$ for $2 \mathrm{~h}$. Incubation was continued overnight after $0.6 \mathrm{mg}$ protease $\mathrm{K}$ was added to the hoogenates. DNA was extracted with phenol: chlorform:isoamyl alcohol (24:25:1). DNA fragments were separated on $2 \%$ agarose gel and detected with a UV trasmilluminator after being stained with ethidium bromide.

Caspase-1 activity assay The caspase- 1 activity assay was performed with an enzyme activity assay kit (Caspase-I/ ICE Colorimetric Assay Kit, BioVision) according to the manufacturer's instructions. Each striatal tissue was homogenized in $500 \mu \mathrm{L}$ cell lysis buffer and centrifuged for $10 \mathrm{~min}$ at $10000 \times g$. The supernatant was transferred to a fresh tube and kept on ice. Protein concentration was determined using BCA kit (Pierce, Rockford, IL). For each $100 \mathrm{mg}$ protein was diluted to $50 \mu \mathrm{L}$ with cell lysis buffer and $50 \mu \mathrm{L}$ $2 \times$ reaction buffer (containing DTT $10 \mathrm{mmol} / \mathrm{L}$ ) was added, then $5 \mu \mathrm{L}$ of the $4 \mu \mathrm{mol} / \mathrm{LYVAD}-\mathrm{pNA}$ substrate $(200 \mu \mathrm{mol} / \mathrm{L})$ and the mixture was inculated at $37^{\circ} \mathrm{C}$ for $1 \mathrm{~h}$. Read samples at $405 \mathrm{~nm}$ in a spectrophotometer (Bio-Rad Smart Spec 3000).

Western blot analysis Western blot analysis was performed as described previously ${ }^{[16]}$. Striatal tissues were homogenized in a buffer containing Tris- $\mathrm{HCl} 10 \mathrm{mmol} / \mathrm{L}(\mathrm{pH}$ 7.4), $\mathrm{NaCl} 150 \mathrm{mmol} / \mathrm{L}, 1 \%$ Triton $\mathrm{X}-100,1 \%$ sodium deoxycholate, $0.1 \% \mathrm{SDS}$, edetic acid $5 \mathrm{mmol} / \mathrm{L}$, PMSF $1 \mathrm{mmol} / \mathrm{L}$, aprotinin $0.28 \mathrm{kU} / \mathrm{L}$, leupeptin $50 \mathrm{mg} / \mathrm{L}$, benzamidine $1 \mathrm{mmol} / \mathrm{L}$, pepstain $\mathrm{A} 7 \mathrm{mg} / \mathrm{L}$. Protein concentration was determined using the BCA kit. Thirty micrograms of protein from each sample was subjected to electrophoresis on a $12 \%$ SDS-PAGE gel using a constant current. Proteins were transferred to nitrocellulose membranes and incubated with anti-p53 antibody (p53, p240, Santa Cruz, CA) in Tris buffered saline containing $0.2 \%$ Tween-20 (TBST) and 3\% nonfat dry milk for $3 \mathrm{~h}$. Membranes were washed and incubated with horseradish peroxidase-conjugated second antibody in TBST containing 3\% nonfat dry milk for $1 \mathrm{~h}$. Immunoreactivity was measured with enhanced chemoluminescent autoradiography (ECL kit, Amersham, Arlington Heights, IL) according to the manufacturer's instructions.

Electrophoresis mobility shift assay Striatal nuclear proteins were prepared as described by Qin et $a l^{[14]}$. Protein concentration was determined with the BCA kit (Pierce, Rockford, IL). Synthetic double-stranded NF- $\kappa$ B and AP-1 oligonucleotidyl probes were purchased from Promega (Madison, WI) and labeled with $\left[{ }^{32} \mathrm{P}\right]$ ATP using T4 polynucleotide kinase (Promega). Nuclear proteins $(6-14 \mu \mathrm{g})$ were incubated with $\left[{ }^{32} \mathrm{P}\right]$ labeled probes $(40000 \mathrm{c} / \mathrm{min})$ for 15 min at room temperature in the binding buffer (Promega). Reaction mixtures were electrophoresed on a $4.5 \%$ non-denaturing polyacrymide gel, then dried and exposed to x-ray film at $-80^{\circ} \mathrm{C}$ with intensifying screens for 24 to $48 \mathrm{~h}$. The results were quantitatively analyzed using an image analyzer (SigmaPlot Pro 4).

\section{Results}

Effects of Ac-YVAD-CHO on QA-induced inter-nucleosomal DNA fragmentation To evaluate the consequences of caspase-1 inhibition on apoptosis, we studied the effect of Ac-YVAD-CHO on QA-induced internucleosomal DNA fragmentation. The results showed that QA $(60 \mathrm{nmol})$ induced intense internucleo-somal DNA fragmentation $24 \mathrm{~h}$ after drug administration. The DNA fragments were generally multimers of 180-200 base pairs, indicating internucleosomal DNA digestion by an endonuclease. QA-induced DNA fragmentation was strongly attenuated by Ac-YVAD$\mathrm{CHO}$ in a dose-dependent manner (Figure 1A). The results also showed that Ac-YVAD-CHO $(4 \mu \mathrm{g})$ inhibited QA-induced DNA fragmentation at all time points examined (12, 24, and $48 \mathrm{~h}$ after QA administration; Figure 1B).

Effects of Ac-YVAD-CHO on a QA-induced increase in caspase-1 activity QA injection significantly activated caspase-1 activity in comparison with saline injected animals $(P<0.05, n=6)$. The increase in caspase- 1 activity induced by QA was significantly inhibited by Ac-YVAD-CHO $(P<0.05, n=6)$; however, pre-treatment with $\mathrm{Me}_{2} \mathrm{SO}$ had no effect on the QA-induced activation of caspase-1 (Figure 2). 

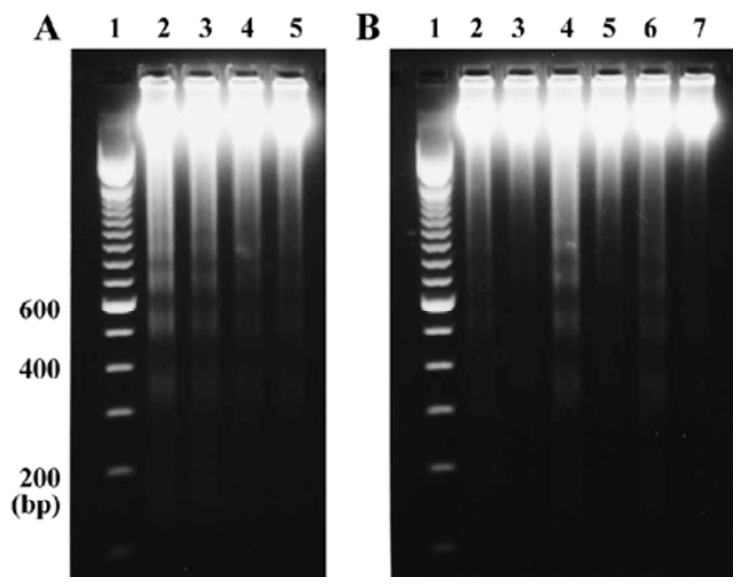

Figure 1. Effects of Ac-YVAD-CHO on QA-induced internucleosomal DNA fragmentation. (A): Rats were pre-treated with intrastriatal injection of Ac-YVAD-CHO $(2-8 \mu \mathrm{g})$ or $\mathrm{Me}_{2} \mathrm{SO}(2 \mu \mathrm{L}) 10 \mathrm{~min}$ before intrastriatal injection of QA $(60 \mathrm{nmol})$ and then killed $24 \mathrm{~h}$ after QA treatment. Genomic DNA from the injected striatum was isolated and electrophoresed on a $2 \%$ agarose gel. Lane 1:100-base pair DNA ladder; 2: QA+Vehicle; 3: QA+Ac-YVAD-CHO (2 $\mu \mathrm{g})$; 4: QA+AcYVAD-CHO (4 $\mu \mathrm{g})$; 5: QA+Ac-YVAD-CHO (8 $\mu \mathrm{g})$. (B): Rats were pre-treated with Ac-YVAD-CHO $(4 \mu \mathrm{g})$ and QA (60 nmol) as described above. Lane 1: 100-base pair DNA ladder; 2: QA+Vehicle, $12 \mathrm{~h} ; 3$ : $\mathrm{QA}+\mathrm{Ac}-\mathrm{YVAD}-\mathrm{CHO}, 12 \mathrm{~h}$; 4: QA+Vehicle, $24 \mathrm{~h}$; 5: QA+Ac-YVADCHO, 24 h; 6: QA+Vehicle, 48 h; 7: QA+Ac-YVAD-CHO, 48 h.

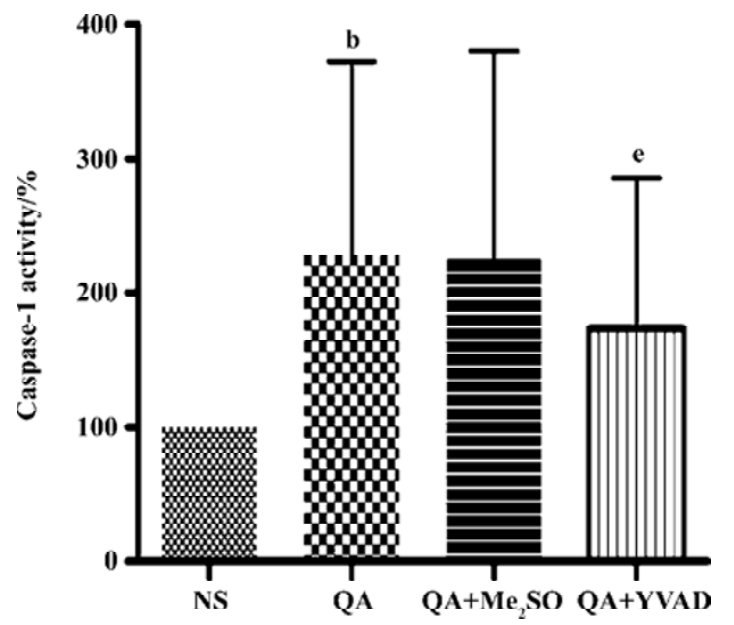

Figure 2. Effects of Ac-YVAD-CHO on the QA-induced increase in caspase-1 activity. The results were expressed as a percentage of control (saline injection) after using statistical analysis. Statistical analysis was carried out with Student's $t$-test. $n=6$. Mean \pm SD. ${ }^{\text {b }} P<0.05$ $v s \mathrm{NS} ;{ }^{\mathrm{e}} P<0.05$ vs QA-treated group.

Effect of Ac-YVAD-CHO on QA-induced p53 induction QA induced significant increases in p53 protein levels by approximately $100 \%$, which was significantly inhibited by Ac-YVAD-CHO $(P<0.05, n=6$, Figure 3$)$.

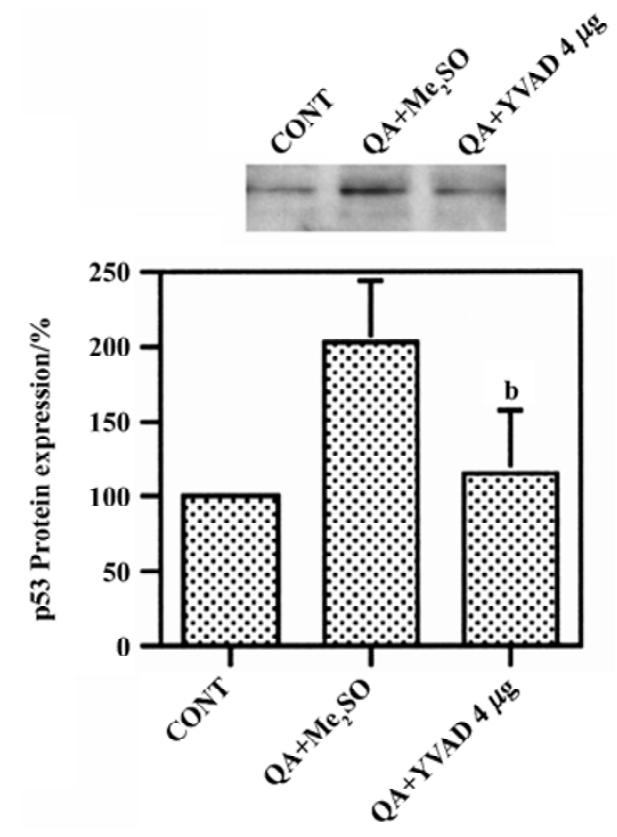

Figure 3. Effects of Ac-YVAD-CHO on QA-induced increase in p53 proteins expression. The results from 4 animals in each group were analyzed with an image analyzer and were expressed as percent of control (untreated animals). Statistical comparisons were carried out with ANOVA followed by Dunnett $t$-test. $n=4$. Mean \pm SD. ${ }^{\mathrm{b}} P<0.05$ vs $\mathrm{QA}+\mathrm{Me}_{2} \mathrm{SO}$ group.

Effects of Ac-YVAD-CHO on QA-induced degradation of IKB- $\alpha$ QA treatment significantly reduced protein levels of I $\kappa$ B- $\alpha$, indicating that I $\kappa$ B- $\alpha$ was degraded after QA treatment. Pre-treatment with various doses of Ac-YVAD-CHO (2-8 mg) had no significant effect on QA-induced degradation of IкB- $\alpha$ (Figure 4).

Effect of Ac-YVAD-CHO on the QA-induced activation of NF- $\kappa \mathbf{B}$ and AP-1 Changes in NF- $\kappa \mathrm{B}$ and AP-1 binding in nuclear extracts were measured by using an electrophoresis mobility shift assay. QA induced dramatic increases in NF$\kappa \mathrm{B}$ binding activity in nuclei. However, Ac-YVAD-CHO (4 $\mathrm{mg}$ ) had no significant effect on QA-induced NF- $\kappa \mathrm{B}$ activation (Figure 5A). Similarly, AP-1 binding activity was increased markedly after QA administration and Ac-YVAD$\mathrm{CHO}$ failed to inhibit the QA-induced activation of AP-1 (Figure 5B).

\section{Discussion}

Apoptotic mechanisms are involved in the degeneration of strial neurons induced by the glutamate receptor agonist QA. In the present study, the role of caspase-1 in QAinduced $\mathrm{p} 53$ upregulation and $\mathrm{NF}-\kappa \mathrm{B}$ activation was investigated using the selective cell-permeable caspase- 1 inhibitor 


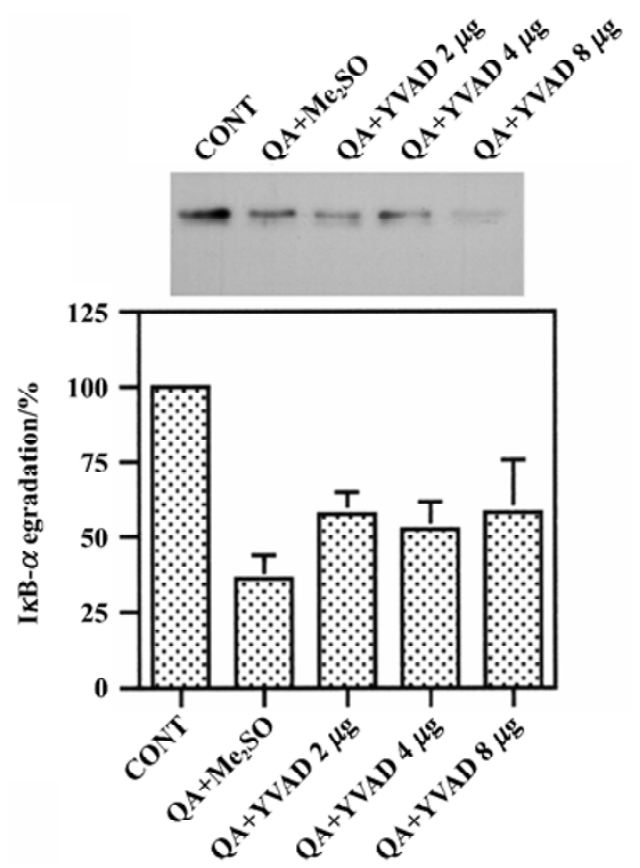

Figure 4. Effect of Ac-YVAD-CHO on the QA-induced degradation

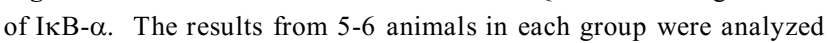
with an image analyzer and expressed as percentage of control (untreated animals). Statistical comparisons were carried out using ANOVA analysis. Mean \pm SD.

Ac-YVAD-CHO. The results of the study showed that pretreatment with Ac-YVAD-CHO dose-dependently inhibited QA-induced internucleosomal DNA fragmentation. AcYVAD-CHO had no significant effect on the QA-induced I $\kappa \mathrm{B}-\alpha$ degradation and NF- $\kappa \mathrm{B}$ activation. However, AcYVAD-CHO partially inhibited QA-induced increase in $\mathrm{p} 53$ protein levels. These results suggest that caspase-1 plays a role in QA-induced p53 upregulation but not QA-induced I $\kappa$ B- $\alpha$ degradation.

It has been reported that glutamate receptor agonists activate NF- $\kappa$ B via the degradation of I $\kappa$ B- $\alpha^{[15,16]}$. Previous studies have further suggested that caspase-3, like protease, is involved in NMDA receptor-stimulated degradation of I $\kappa \mathrm{B}-\alpha^{[18,19]}$. Activation of NF- $\kappa \mathrm{B}$ upregulates c-Myc and p53, indicating that $\mathrm{NF}-\kappa \mathrm{B}$ contributes to excitotoxin-induced apoptosis via the induction of cell cycle regulators ${ }^{[16,17,20]}$. p53 plays a critical role in cell death and survival. Its level is usually regulated by the rate of its degradation ${ }^{[21]}$. Now studies show that the levels of p53 can be regulated by $\mathrm{NF}-\kappa \mathrm{B}^{[16,17,22]}$. In the present study, caspase- 1 inhibitor AcYVAD-CHO had no effect on either QA-induced IkB- $\alpha$ degradation or NF- $\kappa \mathrm{B}$ activation. In contrast, Ac-YVAD-CHO significantly attenuated QA-induced increases in $\mathrm{p} 53$ pro-

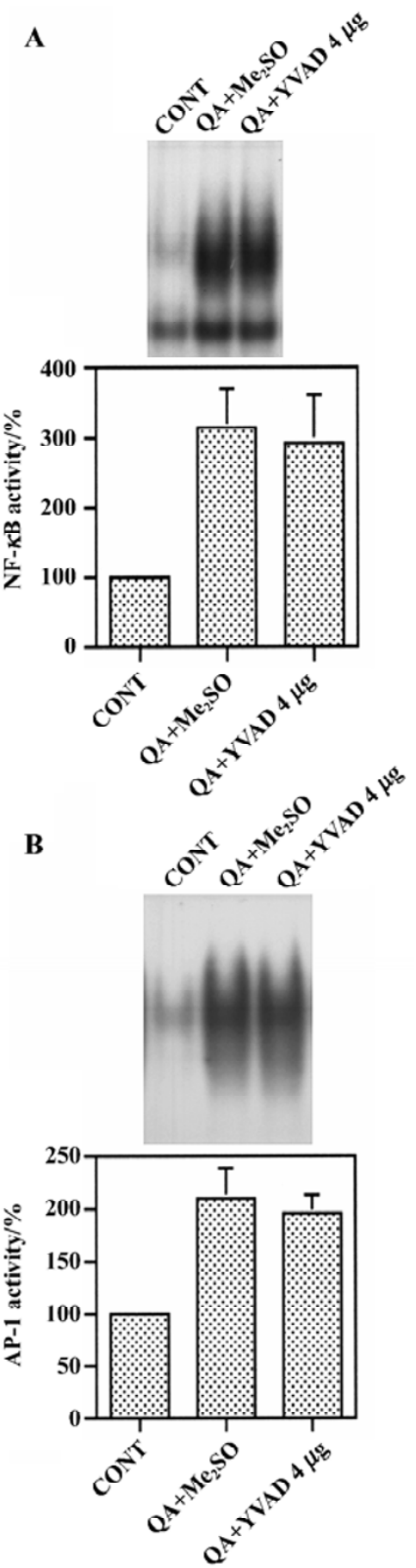

Figure 5. Effect of Ac-YVAD-CHO on QA-induced NF- $\kappa \mathrm{B}$ activation. Vertical bars represent mean \pm SD. $n=6$. Statistical comparisons were carried out with ANOVA analysis. A: Effect of Ac-YVAD-CHO on the QA-induced NF- $\kappa$ B activation. B: Effect of Ac-YVAD-CHO on AP-1 activation.

tein levels and apoptosis. This study indicated that both $\mathrm{NF}-\kappa \mathrm{B}$ dependent and independent mechanisms are involved 
in the QA-induced upregulation of p53 and apoptosis.

In conclusion, we found that the caspase- 1 inhibitor AcYVAD-CHO inhibited the QA-induced increase in p53 protein levels and internucleosomal DNA fragmentation, but had no effect on QA-induced I $\kappa$ B- $\alpha$ degradation and NF- $\kappa \mathrm{B}$ activation. These results suggest that caspase- 1 plays an important role in QA-induced p53 induction and apoptosis, but caspase-1 does not contribute to the QA-induced degradation of I $\mathrm{I} \mathrm{B}-\alpha$ or NF- $\kappa \mathrm{B}$ activation.

\section{References}

1 Zeron MM, Hansson O, Chen N, Wellington CL, Leavitt BR, Brundin $\mathrm{P}$, et al. Increased sensitivity to $N$-methyl- $D$-aspartate receptor-mediated excitotoxicity in a mouse model of Huntington's disease. Neuron 2002; 33: 849-60.

2 Bonfoco E, Krainc D, Ankarcrona M, Nicotera P, Lipton SA. Apoptosis and necrosis events induced, respectively, by mild and intense insults with $N$-methyl- $D$-aspartate or nitric oxide/superoxide in cortical cell culture. Proc Natl Acad Sci USA 1995; 92: 7162-6.

3 Qin ZH, Wang Y, Chase TN. Stimulation of NMDA receptors induces apoptosis in rat brain. Brain Res 1996; 725: 166-76.

4 Simonia NA, Getz RL, Leveque JC, Konradi C, Coyle JT. Kainate induces apoptosis in neurons. Neuroscience 1996; 74: 675-83.

5 Slack RS, Belliveau DJ, Rosenberg M, Atwal J, Lochmuller H, Aloyz $\mathrm{R}$, et al. Adenovirus-mediated gene transfer of the tumor suppressor, p53, induces apoptosis in postmitotic neurons. J Cell Biol 1996; 135: 1085-96.

6 Armstrong RC, Aja TJ, Hoang KD, Gaur S, Bai X, Alnemri ES, et al. Activation of the CED3/ICE-related protease CPP32 in cerebellar granule neurons undergoing apoptosis but not necrosis. J Neurosci 1997; 17: 553-62.

7 Eldadah BA, Yakovlev A, Faden AI. The role of CED-3-related cysteine proteases in apoptosis of cerebellar granule cells. J Neurosci 1997; 17: 6105-13.

8 Jordan J, Galino MF, Prehn JHM, Weichselbaum RR, Beckett M, Ghadge GD, et al. p53 expression induces apoptosis in hippocampal pyramidal neurons cultures. J Neurosci 1997; 17: 1397-405.

9 Sakhi S, Bruce A, Sun N, Tocco G, Baudry M, Schreiber SS. p53 induction is associated with neuronal damage in the central nervous system. Proc Natl Acad Sci USA 1994; 91: 7525-9.

10 Hughes PE, Alexi T, Yoshida T, Schreiber SS, Knusel B.
Excitotoxic lesion of rat brain with quinolinic acid induces expression of p53 messenger RNA and protein and p53-inducible genes Bax and GADD-45 in brain areas showing DNA fragmentation. Neuroscience 1997; 74: 1143-60.

11 Du Y, Bales KR, Dodel RC, Hamilton-Byrd E, Horn JW, Czilli $\mathrm{DL}$, et al. Activation of a caspase 3-related cysteine protease is required for glutamate-mediated apoptosis of cultured cerebellar granule neurons. Proc Natl Acad Sci USA 1997; 94: 11657-62.

12 Guerrini L, Blasi F, Denis-Donini S. Synaptic activation of NF- $\kappa B$ by glutamate in cerebellar granule neurons in vitro. Proc Natl Acad Sci USA 1995; 92: 9077-81.

13 Kaltschmidt C, Kaltschmidt B, Baeuerle PA. Stimulation of ionotropic glutamate receptors activate transcription factor $N F-\kappa B$ in primary neurons. Proc Natl Acad Sci USA 1995; 92: 9618-22.

14 Qin ZH, Wang Y, Nakai M, Chase TN. Nuclear factor- $\kappa$ B contributes to excitotoxin-induced apoptosis. Mol Pharmacol 1998; 53: 33-42.

15 Nakai M, Qin ZH, Chen JF, Wang Y, Chase TN. Kanic acidinduced apoptosis is associated with NF- $\mathrm{BB}$ activation. J Neurochem 1999; 74: 647-58.

16 Qin ZH, Chen RW, Wang Y, Nakai M, Chuang DM, Chase TN. NF$\kappa \mathrm{B}$ nuclear translocation up-regulates c-Myc and p53 during $N$-methyl- $D$-aspartate receptor-mediated apoptosis. J Neurosci 1999; 19: 4023-33.

17 Aleyasin H, Cregan SP, Iyirhiaro G, O'Hare MJ, Callaghan SM, Slack RS, et al. Nuclear factor- $\kappa \mathrm{B}$ modulates the $\mathrm{p} 53$ response in neurons exposed to DNA damage. J Neurosci 2004; 24: 2963-73.

18 Nakai M, Qin Z-H, Wang Y, Chase TN. NMDA and non-NMDA receptor-stimulated $\mathrm{I} \kappa \mathrm{B}-\alpha$ degradation: differential effects of the caspase-3 inhibitor DEVD.CHO, free radical scanvenger OPC14117 and ethanol. Brain Res 2000; 859: 207-16.

19 Qin ZH, Wang Y, Chase TN. A caspase-3-like protease is involved in NF- $\kappa \mathrm{B}$ activation induced by stimulation of $N$-methyl$D$-aspartate receptors in rat striatum. Mol Brain Res 2000; 80: $111-22$

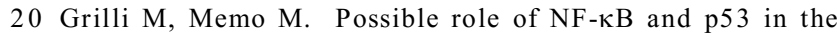
glutamate-induced pro-apoptotic neuronal pathway. Cell Death Differ 1999; 6: 22-7.

21 Levine AJ. p53, the cellular gatekeeper for growth and division. Cell 1997; 88: 323-31.

$22 \mathrm{Wu} \mathrm{H}$, Lozano G. NF- $\mathrm{kB}$ activation of $\mathrm{p} 53$ : a potential mechanism for supressing cell growth in response to stress. J Biol Chem 1994; 269: 20067-74. 